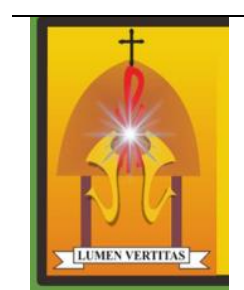

\title{
HAUTEAS IS THE LIVING TREE OF THE DAWANESE PEOPLE
}

\author{
Mikhael Valens Boy \\ Magister dalam Bidang Kitab Suci, Program Studi Ilmu Filsafat, Fakultas Filsafat, \\ Universitas Katolik Widya Mandira Kupang \\ Email: valensboy239@gmail.com
}

\begin{abstract}
Before the arrival and the dominion of the Portuguese and the Dutchmen with its Christianity in the island of Timor, the Dawanese people of Timor have been inheriting and practising its own tribal religion. Even today this native religion has quite strongly and deeply influenced the religious conduct and behaviour of many Dawanese Catholics. These Catholics, beside practising their Catholic faith, they are still practising the "faith and the rite" of Hauteas. Hauteas itself is a strong big stick of wood with three branches, and sorrounding its foot there is a constructed circular altar of stones, that is Faot Makana. Hauteas is always built in the front of the sacred house of the Dawanese that is Uem Leu or Uem Adat. For the Dawanese people, the Hauteas is essentially "the living tree" since it is symbolizing, representing and manifesting the faith and belief of the Dawanese people to their gods. Hauteas functions also as an altar to pray and to offer the sacrifices. Hauteas is the "fountain of life". The "life" of the Dawanese people comes through the trunk of this wood with its three branches. The longer and tallest branch of Hauteas symbolizes and represents the presence of the supreme god (Uis Neno), that is the lord of heaven. One of the lower and shorter branches symbolizes and represents the presence of Uis Pah, that is the lord of earth, and another one symbolizes and represents the presence of Be' $i$-Nai, that is the genealogical ancestors. The altar of stones (Faot Ben Makana) is "the offering and meeting place" between the Dawanese with their gods. The Dawanese people of Timor have a kind of "triune god" that gives and grants upon them life, safety, fertility, welfare, peace and blessings.
\end{abstract}

Keywords: Hauteas, Uem Leu, Faot Makana-Oe Makana, Uis Neno, Uis Pah, Be'i-Na'i, life, safety, fertility, welfare, peace and blessings

\section{Pendahuluan}

Tujuan dari tulisan sederhana ini pertama-tama untuk memperkenalkan kultur keagamaan tradisional Hauteas dari masyarakat Dawan (Atoni) - Timor, yang sudah berabad-abad lamanya dihayati dan masih terus dihayati hingga hari ini. Betapapun kekristenan telah lama dikenal di Timor, yaitu hampir lima ratus tahun sejak kedatangan bangsa Portugal dan kemudian Belanda, namun budaya religius Hauteas masih merupakan jiwa dan habitat dari sebagian masyarakat Dawan, bahkan 
masyarakat Timor. ${ }^{1}$ Banyak teolog Kristen mengkategorikan orang-orang Kristen penghayat budaya religius Hauteas ini sebagai penghayat pola hidup rangkap. ${ }^{2}$ Pertanyaannya, mengapa kekristenan dengan wahyunya yang monotheis belum mampu menuntaskan kebiasaan asli ini? Mengapa banyak orang Katholik yang khusuk berdoa Rosario, ber-Ekaristi toh masih lagi beribadah di Hauteas? Kali ini saya tidak bermaksud untuk menjawabi semua kompleksitas pola hidup rangkap orang beriman. Yang diperjuangkan di sini, adalah pentingnya penemuan nilai-nilai luhur dari kultur religius Hauteas, yang pada gilirannya dapat membantu terjadinya inkulturasi keimanan bagi orang Kristen.
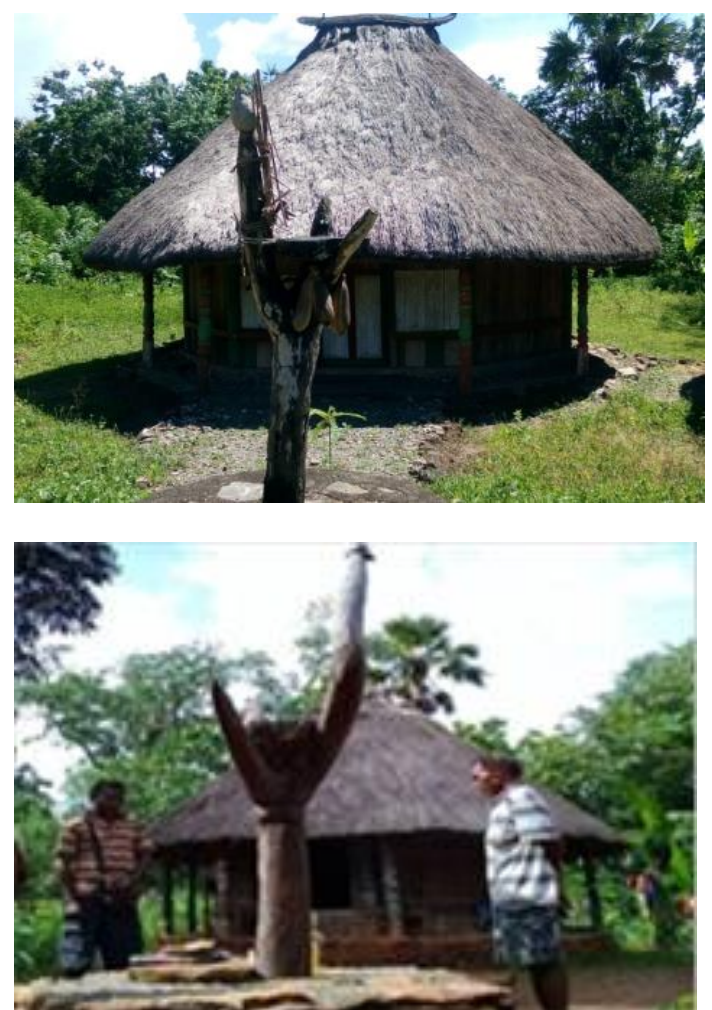

Gambar 1 \& 2. Hauteas di halaman depan dari 'ume adat'.

\section{HAUTEAS}

\subsection{Pemahaman}

Penghayat tradisi religius Hauteas adalah manusia Dawan (Atoni), yaitu suku yang terbesar di pulau Timor bagian barat. Terminologi Dawan bermakna etnis-kultural. ${ }^{3}$ Sebagian besar wilayah barat pulau Timor, mulai dari Kabupaten Timor Tengah Utara hingga Kabupaten Kupang, dihuni oleh Suku Dawan, yang dikenal juga dengan sebutan orang Atoni atau Atoin Meto. Istilah Hauteas adalah kata rangkap dari

\footnotetext{
${ }^{3}$ Gregor Neonbasu, We Seek Our Roots: Oral Tradition in Biboki, West Timor, (Germany: Academic Press Fribourg Switzerland, 2011), p. 263-264
} 
bahasa Dawan yang terkomposisi dari dua kata, yaitu hau atau haub = pohon, kayu; dan teas, yang berarti teras, inti, sari, tongkat. Secara etimologis, Hauteas berarti teras pohon, inti kayu, sari kayu, nadi kayu, pokok kayu yang keras. Secara kultural-religius, Hauteas adalah pokok kayu atau tiang sakral yang bercabang tiga (toef teun), yang menyimbolkan dan menandakan "jiwa dan kekuatan" hidup dari manusia Dawan. Biasanya pohon nikis diupacarakan dan digunakan sebagai tiang sakral Hauteas. Hauteas ditempatkan dan ditanamkan secara kokoh di halaman depan dari Uem Adat atau Uem Le'u, yaitu rumah suku dan karena itu keramat. Tiang sakral bermahkotakan tiga cabang dengan ukuran yang berbeda. Salah satu cabangnya harus lebih panjang/tinggi dibandingkan dengan kedua cabang yang lain dan pada cabang yang tertinggi ditancapkan sebuah kelapa muda. Di antara ketiga cabang ini ditempatkan sebuah batu ceper, dan pada kaki dari Hauteas disusun batu-batu secara simetris bundar yang berfungsi sebagai mezbah atau altar. Susunan batu-batu ceper itu cukup tinggi dan bisa mencapai satu meter tingginya. Bahan-bahan persembahan seperti padi, jagung, hewan kurban, daging, dan lain sebagainya dapat ditempatkan pada altar atau mezbah ini.

\subsection{Teologi Hauteas}

Secara simbolik seluruh batang sakral Hauteas menyimbolkan dan mempresentasikan kehadiran dari pemberi hidup dan pembawa keselamatan masyarakat Dawan. Hauteas melambangkan pokok dan prinsip hidup yang menjadi jiwa, kekuatan dan penopang hidup manusia Dawan. Dalam bahasa Dawan, Hauteas adalah hit beik ma hit matanik, yang berarti 'tenaga dan kekuatan' hidup. Hauteas melambangkan "iman" manusia Dawan, yaitu kepada siapa masyarakat tradisional Dawan percaya. Cabang yang terpanjang (tertinggi) melambangkan dan menghadirkan Uis Neno, yaitu Tuhan Langit atau Uis Neno Mnanu = Tuhan Langit yang tinggi. Salah satu cabang yang lebih pendek melambangkan dan menghadirkan Uis NenoPala, yaitu Tuhan Langit yang pendek, atau Uis Pah, yaitu Tuhan Bumi; sedangkan cabang pendek lainnya menyimbolkan kehadiran Be'i - Na'i = the ancestors, yaitu para leluhur genealogis manusia. Sebuah fatu bena = batu ceper yang ditempatkan di antara ketiga cabang dari Hauteas melambangkan surga/takhta, yaitu tempat pertemuan para leluhur dengan Tuhan Langit (Uis Neno) dan Tuhan Bumi (Uis Pah). Di 'tempat suci' itu leluhur manusia menyampaikan doa dan permohonan manusia kepada Tuhan Langit yang tinggi. Tuhan Langit yang tinggi ini merupakan Allah Tertinggi (Supreme God) bagi manusia DawanTimor. Dalam keyakinan manusia Dawan (Atoin Meto), Tuhan Langit yang tinggi (Uis Neno Mnanu) menguasai 'dunia atas'. Tuhan Bumi (Uis Neno 
Pala/Uis Pah) yang adalah manifestasi dari Tuhan Langit (Uis Neno Mnanu) menguasai 'dunia bawah/bumi'. Sedangkan Bei - Nai (para leluhur) adalah perantara antara manusia dengan Tuhan Langit (Uis Neno Mnanu) dan Tuhan Bumi (Uis Neno Pala). Penancapan sebuah kelapa muda pada ujung cabang terpanjang/tertinggi dari Hauteas melambangkan berbagai rahmat Tuhan yang senantiasa tercurah kepada manusia. Hauteas didirikan di atas sebuah lingkaran/bundaran yang terbuat dari batu-batu, dan itu membentuk dan berfungsi sebagai sebuah altar. Altar ini merupakan tempat pertemuan manusia dengan para leluhur. Pada altar tersebut para leluhur mendengarkan segala doa, harapan, dan permohonan manusia untuk dilanjutkan kepada Uis Neno. Hauteas bersama altarnya merupakan tanda dan simbol kehadiran serta keterlibatan yang ilahi atau realitas adikodrati dengan manusia Dawan dalam seluruh dinamika hidupnya. Secara filosofis Hauteas merupakan perlambang kehidupan dan keharmonisan antara langit dan bumi, Tuhan dan manusia, makro dan mikro kosmos. Melalui tradisi Hauteas manusia menghantar dan mempersembahkan doa dari yang kasat mata kepada yang tak kasat mata atau dari yang kelihatan kepada yang tak kelihatan. Hauteas penuh bergelimang dengan nilai religius dan nilai budaya dari masyarakat manusia suku Atoni, Timor.

\subsection{Perincian Keimanan Hauteas}

Hauteas mengandung dan mengungkapkan iman/kepercayaan manusia Dawan, Timor. Melalui Hauteas manusia Dawan atau Atoin pah meto percaya dan mempercayakan diri kepada pribadi-pribadi "adikodrati" sebagai pemberi hidup dan keselamatan.

\subsubsection{Tuhan Langit (Uis Neno atau Uis} Neno Mnanu)

Dalam sistem religi masyarakat Dawan, Uis Neno merupakan Tuhan tertinggi (Supreme God). Secara harafiah Uis Neno berarti harafiah: 'Tuan atau Tuhan Langit atau Tuhan Hari'. Kata neno punya dua makna: 'langit' dan 'hari'. Berhubungan dengan makna yang kedua, "hari", maka "Tuhan Hari" dianalogikan dan dirujukkan kepada matahari. Uis Neno itu bagaikan matahari. Dalam kosmologi orang Dawan matahari itu sangat berpengaruh terhadap kosmos. Di satu pihak, matahari memancarkan kehidupan dan keselamatan. Akan tetapi, di lain pihak matahari bisa menjadi alasan kelayuan dan kematian, khususnya bagi tumbuhtumbuhan. Uis Neno itu adalah "dewa matahari". Ada berbagai atribut mengungkapkan hakekat Uis Neno, dan berkaitan dengan matahari, Uis Neno itu apinat-aklahat = menyala, bersinar, bercahaya dan membara-membakarmenghanguskan.

Hakekat Uis Neno menurut "tutur adat" orang Dawan: 
- $\quad$ Uis Neno Apinat-Aklaat $=$ Tuhan Langit itu bersinar dan membara. Maksudnya, Tuhan Langit itu mahakuasa dan sumber hidup;

Uis Neno Alut - Anesit $=$ Tuhan Langit itu melebihi dan mengatasi. Maksudnya, Tuhan Langit itu adalah dewa tertinggi (Supreme God);

Uis Neno Afinit-Amnanut $=$ Tuhan Langit itu tertinggi dan terpanjang. Maksudnya, Tuhan Langit itu adalah dewa tertinggi (Supreme God)

- $\quad$ Uis Neno Akubelan-Akuasat = Tuhan Langit itu pemerintah dan penguasa. Maksudnya, Tuhan Langit itu berdaulat dan berkuasa;

Uis Neno Amoet-Apakaet = Tuhan Langit itu pembuat dan pengukir. Maksudnya, Tuhan Langit itu pencipta;

- $\quad$ Uis Neno Alikin-Apean $=$ Tuhan Langit itu peretas dan penebar. Maksudnya, Tuhan Langit itu pemberi hidup dan mengembang-biakkan;

- $\quad$ Uis Neno Ahaot-Afatis = Tuhan Langit itu yang memberi makan dan yang mengasuh. Maksudnya, Tuhan Langit itu pemelihara dan penyelenggara;

- Uis Neno Aneot-Amafot = Tuhan Langit itu penaung dan pelindung. Maksudnya, Tuhan Langit itu pengayom dan pemberi perlindungan;

- Uis Neno Huma Naek-Mata Naek $=$ Tuhan Langit itu berwajah lebar dan bermata besar. Maksudnya, Tuhan Langit itu cerdas dan mahatahu.

- Usi Neno Atukus-Anonot = Tuhan Langit itu penjaga dan penggembala. Maksudnya, Tuhan Langit itu pembimbing dan hakim;

- $\quad$ Uis Neno kan mui Un ma Heun" = Tuhan Langit itu tidak mempunyai awal dan akhir. Maksudnya, Tuhan Langit itu tidak terbatas. Ia adalah alfa dan omega.

Tutur-tutur adat yang dikenakan kepada Usi Neno menunjukkan bahwa manusia Dawan mengimani Uis Neno sebagai dewa tertinggi (supreme god). Tuhan Langit itu berhakekat pencipta, penyelenggara dan penyelamat, namun ia dapat juga menjadi pembawa bencana dan marabahaya. Betapapun suku Atoni tidak memiliki teologi yang utuh dan lengkap karena sikapnya terhadap yang ilahi tumbuh dan berkembang hanya berdasarkan pengalaman hidup kosmik, namun religious feeling-nya akan kehadiran Tuhan Langit yang tinggi di dalam hidupnya sangat tinggi. Manusia Dawan merasakan di dalam hati sanubarinya keberadaan yang ilahi yang menyelenggarakan, menaungi dan mengawasi hidup mereka. Di dalam suka dan duka, mereka mengalami yang ilahi itu sebagai tempat perlindungan dan keselamatan dari malapetaka dan bahaya yang mengancam: bencana alam, penyakit, kekuatan magis, musuh dan lain sebagainya. Rasa ketuhanan yang terpendam di dalam hati sanubarinya 
sulit untuk diungkapkan secara ilmiah, namum sikapnya yang tertib terhadap alam dan manusia menunjukkan bahwa manusia Dawan sungguh mendasarkan hidupnya pada yang ilahi, khususnya Uis Neno. Bagi manusia Dawan, Uis Neno ini adalah deus tremendum dan serentak deus fascinosum.

Tujuan dari upacara ritual yang dilakukan di Hauteas pada umumnya diarahkan kepada Uis Neno dengan maksud memohonkan curah hujan yang cukup dan teratur; untuk memperoleh keturunan; untuk memperoleh hasil bumi yang melimpah; agar mendapat kesehatan badan dan kesejahteraan hidup; dan agar juga terhindar dari bencana dan malapetaka. Upacara ritual keagamaan di Hauteas serentak menghadirkan arwah para leluhur/nenek moyang (smanaf bei'-nai') agar mereka dapat melanjutkan keluh kesah dan permohonan manusia kepada Uis Neno. Fungsi kepengantaran para leluhur ini sangat dominan dalam sistem kepercayaan orang Dawan. Arwaharwah selalu dihadirkan dalam upacaraupacara religius, khususnya yang berhubungan dengan pertanian dan peternakan serta siklus hidup manusia.

Dawan juga percaya akan adanya makhluk-makhluk halus yang dapat mempengaruhi dan bahkan merongrong hidup manusia. Banyak kali penyakit, bencana, kecelakaan dan berbagai kesulitan dianggap sebagai perbuatan makhluk-makhluk halus, akibat manusia tidak memberikan sesajian atau melanggar sebuah aturan kosmik.

\subsubsection{Tuhan Bumi (Uis Neno Pala / Uis Pah)}

Uis Neno Pala atau Uis Pah adalah Tuan/Tuhan Bumi. Bila matahari adalah representasi Uis Neno Mnanu, maka bumi adalah representasi dari Uis Neno Pala/Uis Pah. Bersama Uis Neno, Uis Pah turut membentuk komunitas ilahi, akan tetapi Uis Neno lebih superior. Keduanya memang berbeda dan memiliki eksistensi masing-masing, tetapi tidak dapat dipisahkan. Uis Pah diyakini sebagai penguasa bumi, penguasa mata air, pohon-pohon besar dan gunung-gunung. Itulah alasannya pula, mengapa setiap suku Dawan masing-masingnya memiliki Oe Kanaf Faot Kanaf. Oe Kanaf - Faot Kanat adalah 'legitimasi' keberadaaan suku tertentu di wilayah itu sebagai penduduk asli.

Oe Kanaf artinya sumber mata air dari suku/marga, dan Faut Kanaf artinya batu, gunung, tanah dari sebuah suku. Faot Kanaf-Oe Kanaf adalah 'tanah pusaka' suku tertentu. Manusia Atoni mengimani bahwa pada Faot Kanaf, yaitu batu, bukit, gunung, tanah kapling dari marga dan suku itu bersemayam Uis NenoPala atau Uis Pah. Pada Oe Kanaf, yaitu sumber mata air dari suku, keanggotaan marga atau suku itu disahkan dan disucikan. Inilah "tempat pembaptisan" keanggotaan marga. Secara analogis, Faot Kanat-Oe Kanaf 
"disamakan" dengan "pusat-pusat keagamaan" alkitabiah seperti gunung Sinai, sungai Yordan, Sikhem, Betel, Gilgal, gunung Tabor, Bethlehem, Yerusalem, dan sebagainya.

\subsubsection{Roh Leluhur (Be'i - Na'i)}

Roh para leluhur disebut Bei-Nai. Mereka mempunyai hubungan yang "mutlak" dengan manusia Dawan. BeiNai mampu melindungi dan memelihara anggota keluarga yang masih hidup, dan mereka merupakan "pengantara" yang handal dan terpercaya kepada Uis Neno. Ada satu untaian doa pada akhir setiap Natoni yang berbunyi: "Au ka teva toni ma lasi, maut hi es miteab au toni ma au lasi neu amoet ma apakaet, afinit ma amnanut, apinat ma aklahat" = "Bila tutur dan kata saya tidak sempurna, maka biarlah kamu (para leluhur) yang melanjutkan dan menyampaikannya kepada Tuhan Langit: pencipta dan pemberi hidup; yang tinggi dan menjulang; yang bernyala dan bersinarmembara". Dibandingkan dengan rohroh halus, para leluhur merupakan pengantara yang baik dan terpercaya. Pengantaraan roh-roh halus kurang dan sulit dipercayai walau pun diberi sesajian!

Ada pula sepenggal doa yang dipanjatkan manusia Atoni kepada leluhurnya di depan Hauteas agar memberikan kesejahteraan dan keselamatan kepada pasangan yang baru saja menikah: "Hoe' mnasi mnune, ahunut ma amunit. Nbi oras ije, - hai eim ma mhaek, - nbi hit humak ma hit matak, - he miton ma milile neu kit. Fun hit an mone ma hit an feto, - ntokon bael nen ma nabuab nen. He fe sin manikin ma oetene, - neu sin monik ma sin tolon, - he mfe sin ao mina ma ao leko, - neu noka ma sine, - he napein alekot ma amasat, - neik sin suti-fani ma benas, he nkeo ma naaik,- he nait nfe ma nona,neu sin sufa ma kaun,- neu neno neis namuin,- he nanae ma nasbeb". [Terjemahan secara harafiah: "O...para leluhur, yang tua dan yang muda, yang dahulu dan yang kemudian! Saat ini, kami datang dan berdiri di hadapanmu, untuk menyampaikan dan menunjukkan kepada kita, (bahwa) anak laki-laki kita dan anak perempuan kita, telah berumah tangga dan telah hidup bersama. Semoga mereka diberi "kedinginan dan kesejukan", demi hidup dan masa depan mereka. Supaya mereka diberi tubuh yang sehat dan badan yang segar, agar besok dan lusa, mereka memperoleh yang elok dan yang baik, melalui alat pintal dan kapak serta parang mereka, agar supaya alat pintal menari lancar dan kapak-parang menjadi tajam, agar di kemudian hari mereka dapat memberi warisan, kepada anak-cucu mereka, sehingga anak-cucu mereka terus bertumbuh dan berkembang menjadi kuat dan besar"].

Dalam doa ini dapat ditemukan filsafat dan keimanan orang Dawan akan adanya komunitas kehidupan bersama dengan para leluhur. Di sini leluhur bukan saja menjadi "perantara" ke Uis 
Neno, tetapi juga "ilahi" (roh abadi), dalam arti mereka "mampu" memberi dan menganugerahkan kebaikan dan damai sejahtera kepada anak-cucunya yang masih hidup di muka bumi. Isi dari doa manusia Dawan pada umumnya demi "shalom-damai sejahtera" baginya dan bagi anak-cucu serta keturunan selanjutnya.

\subsection{Manfaat Sosial Tradisi Hauteas Bagi Hidup Manusia Dawan}

Penghayatan tradisi keagamaan Hauteas mempunyai makna sosologis yang besar bagi masyarakat Dawan. Tradisi Hauteas mempersatukan dan mengakrabkan anggota keluarga, klan, marga dan suku. Melalui tradisi Hauteas, anggota-anggota keluarga, klan, marga dan suku yang telah tersebar kemana-mana karena pekerjaan dan perkawinan, dapat berkumpul kembali untuk mengalami persatuan dan kesatuan jiwa dan raga. Tradisi keagamaan Hauteas menciptakan dan menumbuhkan kembali rasa kekeluargaan dan persaudaraan dan persatuan di antara sesama klan, marga dan suku. Persekutuan dan persatuan karena Hauteas pada prinsipnya bukan semata bersifat manusiawi, tetapi serentak merupakan persekutuan dengan "yang ilahi" dan dengan leluhur. Keimanan ini pulalah yang menjadi dasar adanya filosofi orang Atoni: Nekaf Mese, Ansaof Mese = "satu hati dan satu jantung”. Ungkapan nekaf mese ansaof mese bermakna sehidup semati, seia sekata, sekata seperbuatan, sehati sejiwa, bersatu bersaudara dan sebagainya.
Prinsipnya manusia Dawan menghayati persatuan dan persaudaraan bukan hanya sebagai satu moralitas manusiawi tapi juga sebagai moralitas surgawi.

Tradisi keagamaan Hauteas menjadi pula norma kebersamaan dan dengan demikian turut menjamin disiplin hidup manusia Dawan. Melalui tradisi Hauteas, anggota masyarakat Dawan dipandu untuk berpikir, bertindak dan berperilaku secara baik dan benar. Masyarakat Atoni disadarkan selalu untuk bersyukur dan berterima kasih kepada "Tuhan" karena atas rahmat dan berkat yang diperoleh. Salah satu ucapan syukur yang khas ditampakkan pada masa panen jagung atau padi, pen fe'u-aen fe'u. Syukur panen padi dan jagung ini ditandai dengan ritus persembahan di Hauteas. Ritus ini disebut usa ma ta'tek, yang secara harafiah berarti 'menyimpan dan meletakkan' (mempersembahkan). Masyarakat Dawan tidak akan makan hasil kebun sebelum mengadakan upacara usa/ta'tek. Demikian tradisi Hauteas membantu manusia Dawan untuk hidup dalam pengaturan dan pendisiplinan diri yang berkwalitas.

\section{HAUTEAS DAN ALTAR}

Dalam liturgi Katholik, imam mempersembahkan misa kudus yaitu perayaan kurban Kristus di atas sebuah altar. Pada altar itu selalu diletakkan sebuah Salib Kristus yang berkorpus. Sesungguhnya Salib Kristus dalam kesatuannya dengan altar adalah 
kristalisasi iman Katholik akan misteri Paskah Kristus. Demikian secara analogis, Hauteas (tiang sakral) dalam kesatuannya dengan altar batu yang ada pada kaki Hauteas merupakan kristalisasi iman manusia Dawan akan kesatuannya dengan yang ilahi dan leluhurnya sebagai sumber hidup dan keselamatan. Berdasarkan ilustrasi ini, ingin saya ulas "hubungan" antara Hauteas dan "altar" (misbyah atau misbeha) khususnya yang terdapat dalam beberapa teks dari Kitab Kejadian.

\subsection{Dalam Kitab Kejadian}

Pemunculan pertama kali pendirian mezbah bagi Tuhan terjadi persis sesudah peristiwa air bah oleh Nuh sebagai ungkapan syukur dan terimakasih kepada Tuhan atas terluputnya Nuh dan keluarganya dari amukan air bah. "Lalu Nuh mendirikan mezbah bagi TUHAN; dari segala binatang tidak haram dan dari segala burung yang tidak haram diambilnyalah beberapa ekor, lalu ia mempersembahkan korban bakaran di atas mezbah itu" (Kej. 8:20). Demikian upacara ibadat di mezbah Hauteas dilakukan pada hari-hari syukur dan terimakasih kepada Uis Neno dan para leluhur karena adanya hasil panenan; penerimaan anggota baru dalam klan; dan juga karena terluputnya manusia Dawan dari penyakit, mushibah atau malapetaka serta selamatnya anggota klan dalam peperangan. Tentang mempersembahkan korban bakaran di atas mezbah pun dilakukan oleh manusia Dawan pada altar batu di kaki Hauteas.

\subsection{Abraham}

Pemunculan kedua pendirian mezbah dilakukan oleh bapak bangsa, Abraham. "Ketika itu TUHAN menampakkan diri kepada Abram dan berfirman: 'Aku akan memberikan negeri ini kepada keturunanmu'. Maka didirikannya di situ mezbah bagi TUHAN yang menampakkan diri kepadanya" (Kej. 12:7). Abraham mendirikan mezbah bagi Tuhan sebagai ungkapan syukur dan terimakasih atas penampakan Tuhan, yang berarti pula atas penyertaan Tuhan. Demikian ibadat Hauteas dilatarbelakangi oleh ucapan syukur manusia Dawan kepada Uis Neno dan terimakasih kepada leluhur atas penyertaan mereka, betapa pun "perasaan takut" akan Uis Neno juga turut membayangi syukur ini.

Bapak bangsa Abraham lalu mendirikan mezbah lagi bagi Tuhan untuk memanggil nama TUHAN. "Kemudian, ia (Abram) pindah dari situ ke pegunungan di sebelah timur Betel. Ia mendirikan kemahnya dengan Betel di sebelah barat dan Ai di sebelah timur, lalu ia mendirikan di situ mezbah bagi TUHAN dan memanggil nama TUHAN" (Kej. 12:8; bdk Kej. 13:4). Di sini Abraham mendirikan mezbah bagi Tuhan untuk "memanggil nama TUHAN", yaitu untuk berdoa, untuk memanjatkan permohonanpermohonannya kepada Tuhan agar 
didengarkan dan dikabulkan. Demikian dalam ibadat Hauteas, didoakan dan disampaikan permohonan-permohonan manusia Dawan kepada Uis Neno dan para leluhur agar menurunkan rahmat damai sejahtera, khususnya untuk keberhasilan pertanian, peternakan dan keturunan.

Abraham mendirikan lagi mezbah ketika hendak mengorbankan anak tunggalnya, Ishak. "Sampailah mereka ke tempat yang dikatakan Allah kepadanya. Lalu Abraham mendirikan mezbah di situ, disusunnyalah kayu, diikatnya Ishak, anaknya itu, dan diletakkannya di mezbah itu, di atas kayu api. Sesudah itu Abraham mengulurkan tangannya, lalu mengambil pisau untuk menyembelih anaknya" (Kej. 22:9-10). Mezbah (altar) baik dalam Kitab Kejadian maupun dalam agama asli manusia Dawan adalah "lokasi memory dan pertemuan suci" dengan yang Ilahi dan serentak menjadi "lokasi korban dan persembahan" kepada yang Ilahi, dandalam hal ini kepada Yahwe (Allah Israel) dan kepada Uis Neno (dewa tertinggi orang Dawan) serta para leluhur manusia Dawan.

\subsection{Ishak}

Bapa bangsa Ishak mendirikan mezbah sesudah Tuhan menampakkan diriNya kepadanya di Bersyeba. "Dari situ ia (Ishak) pergi ke Bersyeba. Lalu pada malam itu TUHAN menampakkan diri kepadanya serta berfirman: 'Akulah Allah ayahmu Abraham; janganlah takut, sebab Aku menyertai engkau; Aku akan memberkati engkau dan membuat banyak keturunanmu karena Abraham, hambaKu itu'. 'Sesudah itu Ishak mendirikan mezbah di situ dan memanggil nama TUHAN. Ia memasang kemahnya di situ, lalu hamba-hambanya menggali sumur di situ" (Kej.26: 23-25). Bapa bangsa Ishak sebagaimana ayahnya, Abraham, mendirikan mezbah sebagai ucapan syukur atas 'kehadiran' Tuhan di tempat tertentu, dan juga untuk 'memanggil nama Tuhan', yaitu untuk mengekspresikan kontaknya yang tetap dengan Tuhan dalam doa dan permohonan. Di sini tampaknya "mezbah" adalah "tempat permanen yang memprovokasi" kehadiran Tuhan. Dan hal ini sama dengan yang dipikirkan oleh manusia Dawan akan peran Hauteas (tiang sakral) sebagai "lokasi tetap" bagi kehadiran Uis Neno dan para leluhur.

\subsection{Yakub}

Pendirian mezbah/altar oleh bapak bangsa Yakub menunjukkan semakin mewujudnya janji Tuhan akan kepemilikan tanah terjanji. "Kemudian dibelinyalah dari anak-anak Hemor, bapa Sikhem, sebidang tanah, tempat ia memasang kemahnya, dengan harga seratus kesita. Ia mendirikan mezbah di situ dan dinamainya itu 'Allah Israel adalah Allah"” (Kej. 33:19-20). Di mana ada "keringat dan darah" dan di mana ada "kediaman" manusia, di situ Yakub mendirikan mezbah bagi Tuhan. Yakub lalu menamai mezbah itu dan mungkin juga tempat yang dibelinya itu dan 
padanya dibangun kemahnya, 'Allah Israel adalah Allah' ('EL 'ELOHE 'ISRA'EL) - (WAYYESEB-SAM MIZBEAH WAYYIQRA-LO 'EL 'ELOHE 'ISRA'EL). Demikian juga pada semua rumah adat (Uem Le'u), yaitu 'representasi permanensi' hidup dan karya manusia Dawan, di situ didirikan Hauteas, yaitu 'mezbah' orang Dawan.

Mendirikan mezbah sebagai "memory" dan "syukur" akan kehadiran Allah dan akan pengalaman rohani karena bertemu dengan Tuhan, juga dilakukan oleh Yakub, sebagaimana telah dilakukan oleh leluhurnya, Abraham. "Allah berfirman kepada Yakub: 'Bersiaplah, pergilah ke Betel, tinggalkah di situ, dan buatlah di situ mezbah bagi Allah, yang telah menampakkan diri kepadamu, ketika engkau lari dari Esau, kakakmu" (Kej. 35:1). Di mana dan kemana pun Yakub berjalan dan memasang kemahnya (menetap), hubungan dengan Tuhan tetap berkumandang dan memory serta syukur kepada Tuhan senantiasa bergaung! Itulah juga spiritualitas manusia Dawan, ke mana pun ia pergi dan di mana pun ia berada, hatinya tetap terpaut dengan Hauteas, yaitu altar batu bermahkota tiang sakral di depan Uem Le'u, karena itulah "pohon kehidupannya" (the living tree), yaitu Uis Neno, Uis PahmaBei-Nai = Tuhan Langit, Tuhan Bumi dan para Leluhur, yang mengalirkan kebaikan dan keselamatan bagi manusia Dawan.

\section{Kesimpulan}

Studi singkat tentang hubungan antara "kebenaran dan fungsi teologis" dari MIZBEAH (Altar) dalam beberapa teks dari Kitab Kejadian dengan AltarHauteas dari manusia Dawan menunjukkan adanya beberapa kesamaan visi dan misi di antara manusia Yahudi dan manusia Dawan. Altar dalam kedua "kebudayaan" ini pertama-tama mengekpresikan kehadiran yang Ilahi dan merupakan sarana suci, yaitu tempat pertemuan dengan yang Ilahi. Tuhan dan Uis Neno dihadirkan melalui "persembahan dan kurban" di Altar. Altar adalah "gereja mini", yaitu tempat terjadinya pertemuan antara manusia beriman dengan Tuhannya. Di atas Altar ini disampaikan doa-doa dan permohonan-permohonan manusia agar dapat dikabulkan. Altar dalam kedua "kebudayaan" ini merupakan "tempat pengakuan iman" akan kehadiran "Tuhan" yang menyelamatkan. Karena itu, Altar kapan dan di mana pun merupakan "memory" akan kehadiran "Tuhan" dan serentak "ucapan syukur" kepadaNya.

\section{Daftar referensi}

\section{Kamus}

Buttrick, George Arthur Cs (Ed.), The Interpreter's Dictionary of the Bible, 
(Abingdon Press: Nashville, United States of America, 1991)

Buku

Bakker, Y.W.M., Filsafat Kebudayaan Sebuah Pengantar, (Yogyakarta: Kanisius, 1984).

Agama Asli Indonesia, (Yogyakarta: Seri puskat No 95, sekolah Tinggi Pradnyawidya, 1976)

Bergant, Dianne \& Robert J. Karris (ed.), Tafsir Alkitab Perjanjian Lama, (Yogyakarta: Kanisius, 2002)

Jebadu, Alex, Bukan Berhala! Penghormatan Kepada Para Leluhur, (Maumere: Ledalero, 2009).

Koentjaranigrat, Beberapa Pokok Antropologi Sosial, (Jakarta: PT Dian Rakyat, 1981).

Lake, Reginaldo Christophori. 2014. "Konsep Ruang Dalam dan Ruang Luar Arsitektur Tradisional Suku Atoni di Kampung Tamkesi di Pulau Timor." EJournal Graduate Unpar 1 (2): 61-74. http://journal.unpar.ac.id/index.php/unpa rgraduate/article/view/842/829.

—. 2015. Gramatika Arsitektur Vernakular Suku Atoni Di Kampung Adat Tamkesi Di Pulau Timor. Yogyakarta: CV. Sunrise.

—. 2016. “Tata Spasial Arsitektur Tradisional Suku Atoni Di Kampung Tamkesi Pulau Timor." ATRIUM -
Jurnal

Arsitektur. https://doi.org/10.21460/atvm.2016.21.3.

Lake, Reginaldo Christophori. 2014. 'Konsep Ruang Dalam Dan Ruang Luar Arsitektur Permukiman Tradisional Suku Atoni Di Kampung Adat Tamkesi Di Pulau Timor'. Universitas Katolik Parahyangan.

Neonbasu, Gregor, We Seek Our Roots: Oral Tradition in Biboki, West Timor, (Germany: Academic Press Fribourg Switzerland, 2011)

, Citra Manusia Berbudaya, Sebuah Monografi tentang Timor dalam Perspektif Melanesia, (Jakarta: Antara, 2017) (editor), Rm. Valens Boy, Pr., Pemikiran Dualistis-Kosmis Masyarakat Biboki", dalam, AA. VV., Agenda Budaya Pulau Timor (1), (Timor: Komisi Komunikasi sosial Provinsi SVD Timor, 1990).

Nordholt, H.G. Schulte, The Political System of the Atoni of Timor, (Driebergen, Netherlands: Offsetdruk Van Manen \& Co, 1996)

Tanouf, Paulus Sako, Mengintegrasikan Ibadat "Hauteas" ke dalam Iman Kristen di Paroki Kiupukan Timor (Skripsi), (Yogyakarta: Pradnya Widya, 1983). 


\section{Biodata Penulis}

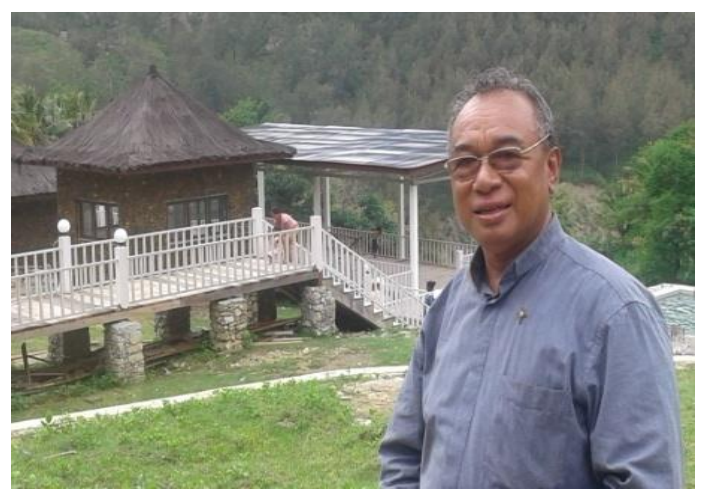

Nama : Rm. Mikhael Valens Boy, Lic.Bib.

TTL : Manufui, TTU-Timor, 23 September 1959

Tamatan: Pontificio Istituto Biblico Roma/Italia (1994)

Tugas : 1. Pendidik/Formatur caloncalon imam di Seminari Tinggi Santo Mikhael Kupang

2. Dosen Kitab Suci pada Fakultas Filsafat Unwira Kupang dan Seminari Tinggi Santo Mikhael Kupang, serta Stipas Kupang dan Kefa 